\title{
Development of a Tool Cost Optimization Model for Stochastic Demand of Machined Products
}

\section{Francisco G. Pantoja1, Victor Songmene1, Jean-Pierre Kenné1, Oluwole A. Olufayo1, Michael Ayomoh ${ }^{2}$}

\author{
${ }^{1}$ Mechanical Engineering Department, École de Technologie Supérieure (ÉTS), Montreal, Canada \\ ${ }^{2}$ Industrial and Systems Engineering Department, University of Pretoria, Pretoria, South Africa \\ Email: francisco.gonzalez-pantoja.1@ens.etsmtl.ca, Victor.Songmene@etsmtl.ca, jean-pierre.kenne@etsmtl.ca, \\ oluwole-ayodeji.olufayo.1@ens.etsmtl.ca,michael.ayomoh@up.ac.za
}

How to cite this paper: Pantoja, F.G., Songmene, V., Kenné, J.-P., Olufayo, O.A. and Ayomoh, M. (2018) Development of a Tool Cost Optimization Model for Stochastic Demand of Machined Products. Applied Mathematics, 9, 1395-1423.

https://doi.org/10.4236/am.2018.912091

Received: November 12, 2018

Accepted: December 25, 2018

Published: December 28, 2018

Copyright $\odot 2018$ by authors and Scientific Research Publishing Inc. This work is licensed under the Creative Commons Attribution International License (CC BY 4.0).

http://creativecommons.org/licenses/by/4.0/

\begin{abstract}
Cutting tool management in manufacturing firms constitutes an essential element in production cost optimization. In order to optimize the cutting tool stock level while concurrently minimizing production costs, a cost optimization model which considers machining parameters is required. This inclusive modeling consideration is a major step towards achieving effectiveness of cutting tool management policy in manufacturing systems with stochastic driven policies for tool demand. This paper presents a cost optimization model for cutting tools whose utilization level is assumed to be optimized in respect of the machining parameters. The proposed cost model in this research incorporated the effects of diversified machining costs ranging from operational through machining, shortage, holding, material and ordering costs. The machining of parts was assumed to be a single cutting operation. Holt-Winters forecasting technique was used to create a stochastic demand dataset for a test scenario in the production of a high-end automotive part. Some numerical examples used to validate the developed model were implemented to illustrate the optimal machining and tool inventory conditions. Furthermore, a sensitivity analysis was carried out to study the influence of varying production parameters such as: machine uptime, demand and cutting parameters on the overall production cost. The results showed that a desired low level of tool storage and holding costs were obtained at the optimal stock levels. The machining uptime had a significant influence on the total cost while tool life and cutting feed rate were both identified as the most influential cutting variables on the total cost. Furthermore, the cutting speed rate had a marginal effect on both costs and tool life. Other cost variables such as shortage and tool costs had significantly low effect on the overall cost. The
\end{abstract}


output trend showed that the feed rate is the most significant cutting parameter in the machining operation, hence influencing the cost the most. Also, machine uptime and demand significantly influenced the total production cost.

\section{Keywords}

Inventory, Tool Cost Optimization, High Value Product, Stochastic Demand, Machining Parameters

\section{Introduction}

Research in the field of cost optimization modelling for stochastic inventory management and control has significantly intensified over the past few decades [1]. The ability to minimize the overall production cost of a machining process while adapting to the ever growing levels of stochasticity in the open market can be considered a major step towards its competitiveness. This capability must, however occur without adversely affecting throughput and production quality amidst multiplicity of inherent market conditions. Machining operations generally constitute a large segment in the manufacturing sector with costing effectiveness serving as a critical success factor. In a machining process, the cutting tool represents an essential element to the entire machining system. This is so because its effect is directly linked to a multiplicity of factors such as: the quality of finished product, cycle time of operation and ultimately the cost of machining amongst others. The significance of the influence of machining parameters on the cutting tool, workpiece and other machining components during an operation is quite crucial to deciding the overall production cost. Some notable components that make up an ideal machining operation are as presented in Figure 1. The optimum behavior of a machining operation can be influenced by any one of these member elements.

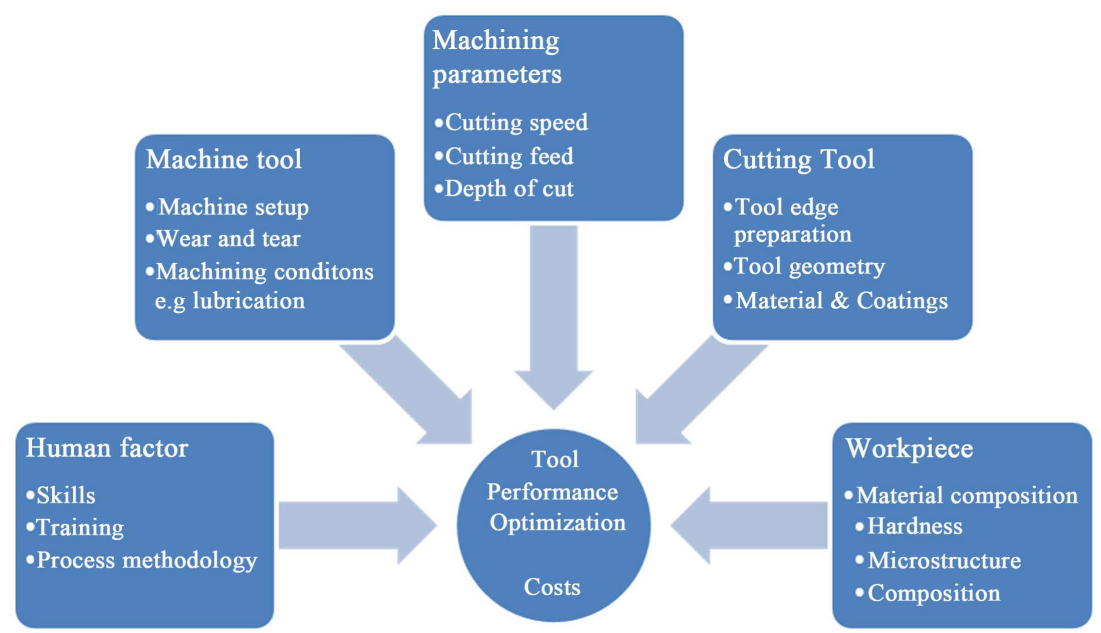

Figure 1. An illustration of factors influencing tool performance optimization. 


\subsection{Predictive Challenges to Manufacturing}

Companies that focus on industrial metal works are often faced with predictive challenges even though there are several quantitative techniques that can be used to improve production processes such as forecasting, probability distributions and optimization related methods amongst others [2]. Very often, applicability within this research space can be limited hence, resulting in a significant production planning problem. Some of these problems are traceable to inefficiencies in the administrative and production processes derived from a poor strategic planning.

In most companies, the behavior of product sales is random, since it is difficult to absolutely predict demand to determine sales. Due to this challenge, the focus is often placed on alternate areas where the lack of a sound process design can be mitigated and controlled. Some of these areas include:

- Production: The lack of a future programming and being left with the expectation of the needs of the clients, manufacturing companies are forced to fulfill the demand of their clients by incurring additional time in the productive processes.

- Inventories. To the poor management of inventory levels, such as the case of high inventory level, this causes high costs and prevents the expansion of the business.

- Finances: Given the high costs of inventories, companies limit their growth in the purchase of new equipment to make production processes more efficient.

To mitigate these and other problems caused by poor planning of the production, it is necessary to design a methodology that provides accurate predictions of the sales of industrial metal mechanical products or mitigate alternate costs generated elsewhere in production [3]. Actual modeling of industrial systems is complicated because of the variability of factors, in many cases it is necessary to make complex combinations of several distribution functions to resolve such problems.

\subsection{Optimization Modelling in Manufacturing}

Existing machining models more often than not, are seen to be analyzing the combination of different cutting materials by focusing on their conditions while conducting analytical, numerical, empirical and artificial intelligence based observations. Robust predictive models are often required to accommodate the complex interaction that exists amongst the trio of a workpiece, the cutting tool and the machine tool [4] [5] [6] [7].

Modeling a cutting process often constitute integrating a system's planning process to improve productivity and enhance product quality. However, to have a significant progress in the modelling of machining processes, especially on metallic work pieces, some notable variables capable of improving the quality of output should be taken into cognizance. Some of these include the effect of 
stress, strain rate and temperature amongst others. From the point of view of demand, when a product with intricate properties such as high strength (e.g. aerospace superalloys) is seasonally or randomly produced, it often becomes difficult for industries machining these materials to adequately estimate the quantity of cutting tools needed to meet the demand. On the other hand, working with high strength materials increases the tendency of tool penalty cost due to short tool life. These effects are central to the increase in the cost of products and a reduction in the overall profit margin. These costs could be associated with storage costs, ordering costs, stock-out or shortage costs.

\subsection{Recent Studies on Cost Optimization in Machining}

Traditional procurement policies are subjective and often premised on periodic supply decisions. These policies are usually based on simplified and idealistic assumptions, as well as on the expected cost criterion, without considering machining factors as well as the finished goods throughput. Some research works [8] [9] [10] [11] [12] have considered more inclusive views into production cost in manufacturing by considering machining conditions. However, the need for a more generalized and adaptable model based on a stochastic demand is needed to optimize production cost in the manufacturing sector.

The rate of tool depletion was found to be a function of tool life and machining conditions. Finding the optimal machining conditions related to tool life and obtaining the optimal order quantity could stabilize cycle length and ordering cycle. A study into production cost in the milling of titanium alloys by considering machining conditions, was conducted by Conradie, Dimitrov and Oosthuizen [12]. In their paper, they designed a cost model which considered pre-cost of manufacturing and auxiliarycost incurred based on machining parameters. Their approach generated means to estimate the cost of titanium milling based on actual machining and pre-manufacturing conditions. Furthermore, due to tools supply unpredictability and market demand variability, numerous researchers have sought to design models which would be used to maximize the efficiency in tool management to mitigate the adverse costs incurred in shortage conditions [9] [10] [11].

$\mathrm{Li}$, Sarker and $\mathrm{Yi}$ [9] in their research into an optimal stocking policy for machining tools, designed a model for stochastically distributed demand and tool lifespan. Their model considered the economic penalty for tool breakdown and its influence on lifespan. They also investigated these effects under a certainty distributed demand scenario [10]. Kouedeu, Kenne, Dejax, Songmene and Polotski [8] in their research on stochastic optimal control of manufacturing systems under production-dependent failure rates, proposed a stochastic dynamic programming formulation and derived numerical optimum policies to satisfy the challenge. Their research focuses on a part inventory production policy, however it does not take into consideration in its estimation the influence of the machining parameters. 
In their research work on cost modelling in milling operations, Parent, Songmene and Kenné [11] used an optimization technique premised on operations research to minimize machining time and evaluate the cost of milling operation hence, demonstrating the practicality of the algorithm in solving cost related problems and as a decision-making aid for a central controller flexible manufacturing cell. Their approach yet only considers an optimization of the machining cost in the overall production cost and ignores the inventory management. This approach can be deployed for analysis of the impact of setup time while computing for the capacity of a system emanating from a new design and in determining the manufacturing price of parts.

The above mentioned works, as most resources from the literature, do not consider the attributes that influences the productive length of a tool-life while solving the general optimization problem. It is however important to recognize that the tool-life productive length has a great impact on tool procurement and management of its inventory systems as well as indirectly influence total operating cost.

\subsection{Problem Statement}

Based on the reality of market variability, which has got so much impact on production processes, modern day manufacturing firms are faced with a rising level of supply uncertainty and demand variability. These fluctuations are characterized with challenges capable of impacting negatively on the optimum performance level and general sustainability of the manufacturing sector. Industrial firms involved in the production of high-valued parts such as the automotive or aerospace industry amongst others are often posed with these challenges [13]. These firms often seek to identify optimum machining parameters to increase tool life while maintaining a high quality production level. Optimization of machining time as well as tool inventory cost management are key factors for attaining high production efficiency for these high-value parts. A functional tool optimization policy capable of reducing costs and sustaining the overall tool optimum conditions has become a major priority in production systems functionality.

Other factors of significant importance in manufacturing processes include machine unit costs, machine uptime costs, ordering costs and lead-time due to their impact on procurement, tool inventory policy and influences on tool lifespan. These considerations if well managed, can reduce the costs associated with production activities, decrease the levels of inventory of tools with low demand and increase the level of service for products considering their seasonality and cyclicality.

This paper presents a combined tool acquisition and cost optimization model capable of predicting and reducing the degree of uncertainty in demand. With this collective information, this will assist in determining the lot-sizing and cycle-time of cutting tools for a better manipulation of the supply chain system. 
This paper develops a nonlinear cost optimization model based on an inventory policy for cutting tools at optimum machining parameters for the production of high-value mechanical parts. Finally, the study inclusively offers information to a production manager regarding the life of his cutting tools in a production process and permits the flexibility to adapt a production process to suit demands consumer requirements.

Figure 2 shows a flowchart that depicts the overall production cost optimization process developed in this study. The optimization process carried out using LINGO software utilized a combined modelling effect of cost minimization and optimum quantity computation as presented in Figure 2. This results in a minimized production cost and optimized ordering quantity. However, these are achievable only when the ordering quantity is optimized.

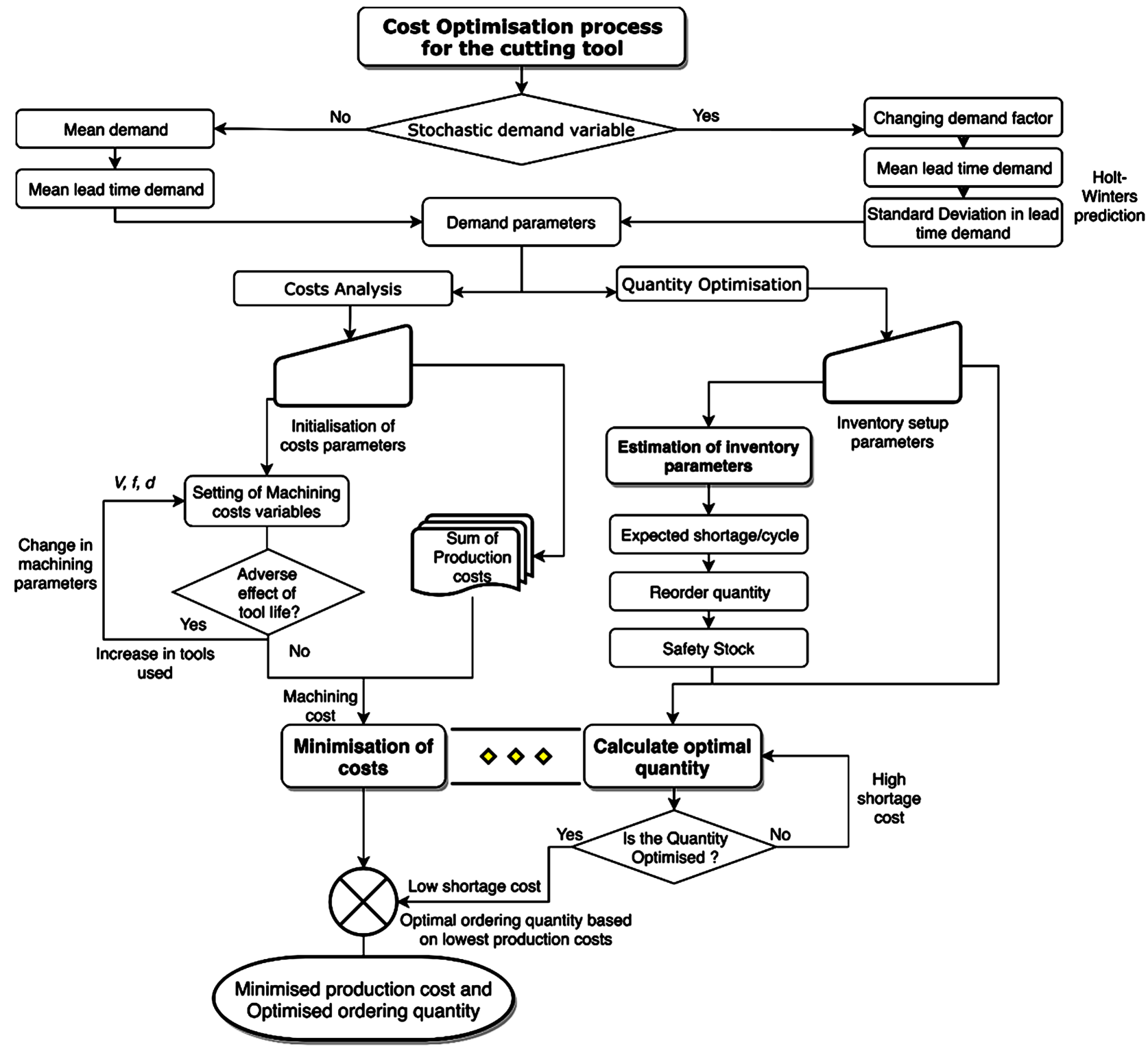

Figure 2. Flowchart of the proposed cost optimization process. 


\section{Model Formulation}

In this section, the model development is introduced with the mathematical formulations, assumptions and constraints. Prior to the model formulation, an illustration of the interaction between main cost components and effect of cost modelling is presented as seen in Figure 3. Herein, the dynamical relationship amongst cost, productivity and basic machining parameters are presented. The optimization process of the model in this research seeks to find the lowest point on the total cost curve amidst diverse production costs. This point marks the beginning of the high efficiency zone in choice of machining parameters where efficient machine and tool life utilization is achieved.

From Figure 3, it could also be seen that the drop in total cost crosses the rising productivity of operations hence, creating an efficient range in production. A subset of this range was found between the lowest cost and highest productivity for the highest machining efficiency. This range is based on a set of machining parameters which indicates the most favorable machining conditions. Beyond the efficient performance zone, the occurrence of severe tool damage creates a proportionate rise in production costs and drop in productivity. On the other hand, below the optimal machine utilization point, the tool utilization is not maximized hence leading to a reduction in tool costs yet resulting in a relatively high machining costs due to poor efficiency.

\subsection{Hypothesis}

This sub-section presents the assumptions considered in the model development process:

1) Tool orders are made on request and not in predefined cyclic batches.

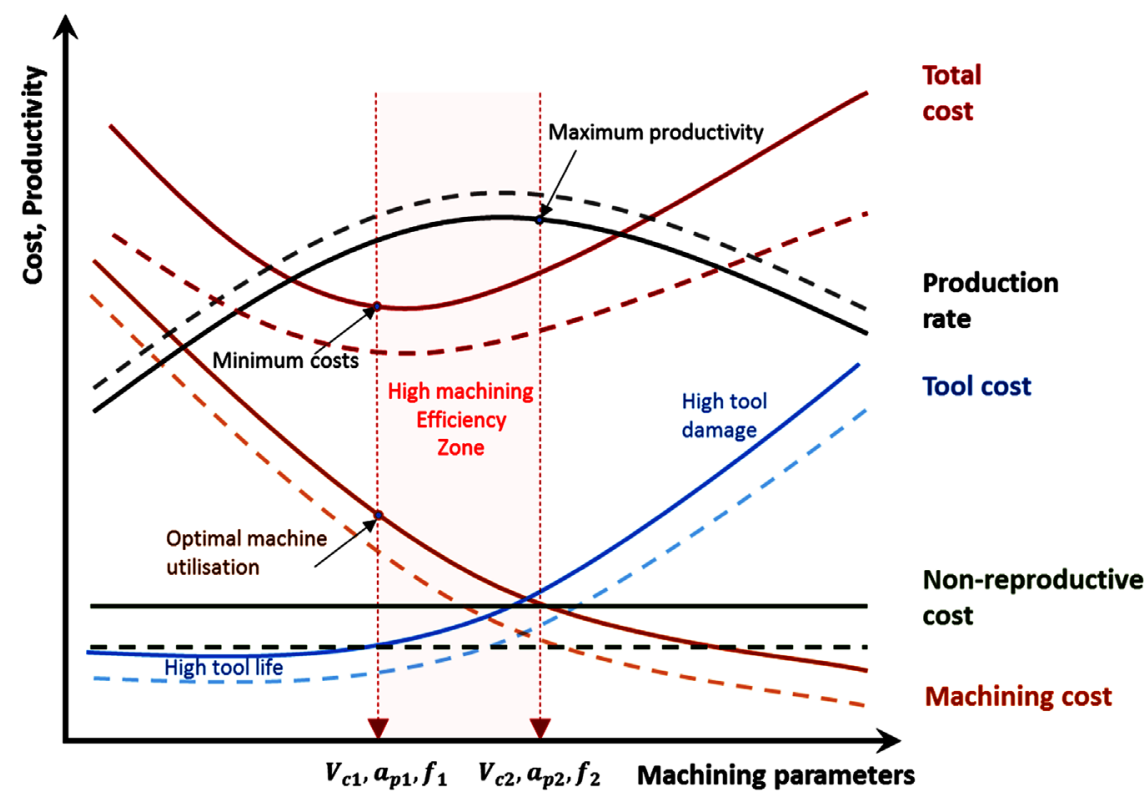

Figure 3. Schematic illustration of interaction between main cost components and effect of cost modelling (adapted from [12] [14]). 
2) The cutting operations tools are mainly divided into two groups, namely: tools for roughing and finishing operations. However, this research will focus on the use a single cutting operation.

3) Once a cutting tool has reached its life span, it is no longer used to avoid tool breakage and the occurrence of a defective process. This also eliminates the penalty cost for tool break.

4) The life span of a tool is considered based on empirical models with the experimentation of similar conditions.

5) Tool vendors are located nearby resulting in a fixed lead time. Hence, all tool demands are satisfied in real-time without any need for back orders.

6) Labor cost is included within machine usage cost and considered to be a constant.

7) Inventory is considered as the average between the initial and final inventory.

8) The demand of part product is random, however, it presents patterns of seasonality, cyclic tendencies that can be followed through forecasting methods such as triple exponential smoothening as premised in (Holt-Winter's Method). Some examples of these patterns are festive yearly seasons, economicfactors, recession and inflation.

9) Machine time used is inclusive of both operational, setup and installation time.

10) Price per unit product is constant

11) Ordering costs are constant

12) The holding cost is a constant and includes both the warehouse and preservation costs.

13) Initial purchases are below demand quantity.

\section{Objective Function}

The focus of this research is to optimize production by obtaining the minimum total cost of operations supported by the inventory system as a complete manufacturing process. This can be represented by an objective function which consists of the cost optimizations elements, these are; the cost of operations, cost of holding, cost of shortage, annual ordering and raw material costs.

Total cost $=$ operational cost + shortage cost + holding cost

$$
\text { + raw material + ordering cost }
$$

$$
\mathrm{TC}(\$)=C_{o p}(\$)+C_{s h}(\$)+C_{h}(\$)+C_{B}(\$)+C_{o}(\$)
$$

${ }^{*} \mathrm{TC}=$ total cost of production in over a production time period $\mathrm{i}$.

The next sub-sections present the details of the elements of the objective function:

\subsection{Cost Optimization Elements}

\subsubsection{Operational Cost}

Machining time is vital in determining the factor of tool life. The cutting time 
during production is defined by the material volume to be cut (Length $\times$ Width $\times$ Height) and the depths of cut (radial and axial) as presented in Figure 4. A representation of Taylor's extended tool life model was applied in this research. The machining workpiece in this research is a rectangular prism which requires different operational schedules ranging from rough cuts through smoothened finish cuts. This research would however focus on the rough cut hence a single cutting operation. The decision variables associated with the material removal process include: width of cut $\left(w_{r}\right.$ and $\left.w_{f}\right)$, depth of cut $\left(d_{r}\right.$ and $\left.d_{f}\right)$ and feeds $\left(v_{f r}\right.$ and $\left.v_{f f}\right)$.

To estimate the life span of a tool using Taylor's empirical model as presented in Equation (2), it is necessary to determine the tool cost. The following equations are a derivation of the original Taylor's model:

$$
t_{0}=\frac{k}{v^{\alpha} f^{\beta} d^{r} w^{\varepsilon}}
$$

In application for milling operations, the tool life expression $\left(t_{0}\right)$ was extended by adding the radial width of cut with $\alpha, \beta$ and $\varepsilon$ serving as parametric constants. Equations based on this type of operation could be devised for either roughing or finishing operations i.e. $t_{0 r}$ or $t_{0 f}$. However, this research is focused on the roughing operation as presented in Equation (3) below:

$$
t_{0 r}=\frac{k}{v_{r}^{\alpha} f_{r}^{\beta} d_{r}^{\gamma} w_{r}^{\lambda}}
$$

The parametric constants defined in this model need to be obtained through experimentation due to the fact that the machining conditions such as the tool material-make, workpiece, cutting fluid, rigidity of the assembly and the system vibration amongst other factors, vary significantly from one machine to the other. These can be determined using a statistical design of experiment (DOE) [11].

The cost of tools utilization per hour is defined here as the ratio of the current market price to the tool life as presented in Equation (5). The tool life is usually expressed in terms of the operations the tool is subjected to over time:

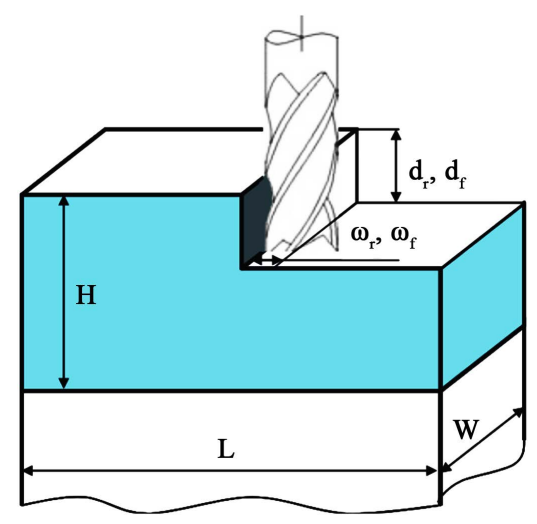

Figure 4. Schematic illustration representation of the material volume to be machined [11]. 


$$
c_{h r}=\frac{c_{p r}}{t_{0 r}}
$$

In this research, the primary focus is the cutting operation. Apart from identifying and analyzing the cutting operations, a special consideration is also given to the respective quantities of cutting tools $\left(Q_{p}\right)$ deployed during the overall production task. A combination of all these results in the models below:

$$
\text { operational cost }=C_{o p}=c_{(r, f)} \cdot Q_{p}
$$

where,

$$
\begin{gathered}
c_{r}=\left(k_{0} \cdot t_{o p r}+c_{h r} \cdot t_{o p r}\right) \\
c_{f}=\left(k_{0} \cdot t_{o p f}+c_{h f} \cdot t_{o p f}\right) \\
Q_{p}=Q_{r}(\text { roughing })+Q_{f}(\text { finishing })
\end{gathered}
$$

where $Q_{f}=0$ in roughing only operations.

Thus:

$$
C_{o p}(\$)=\left(k_{0} \cdot t_{o p}+c_{h r} \cdot t_{o p}\right) \cdot Q_{p}
$$

\subsubsection{Holding Cost}

The holding cost represents all the costs associated with the storage of the inventory until its depletion. These costs usually include tied-up capital, space, insurance, protection, taxes attributed to storage amongst others. The holding cost can be assessed either continuously or on a period-by-period basis. A common consideration for the holding cost is that an initial inventory level exists at the beginning of every period. Based on this, the inventory cost at the beginning of a period I can be obtained from:

$$
C_{h}(\$)=c_{h}\left\{I_{i}+Q_{s}\right\}
$$

where $I_{i}$ is considered as the average inventory level required to avoid shortage of cutting tools. This is computed based on the summation of the initial and final inventory levels divided by two.

$$
I_{i}=\frac{\left(I_{\text {initial }}+I_{\text {final }}\right)}{2}
$$

Furthermore, $\bar{I}_{i}$ as presented below, represents the total amount of tools required to meet the demand for a given product.

$$
\overline{I_{i}}=Q_{s}+I_{i}
$$

In addition, considering the likely physical limitations of a warehouse in terms of its holding capacity, the capacity of storage can be represented as:

$$
\overline{I_{i}} \leq A_{i}
$$

Considering that the average inventory, we can add it directly to the objective function as follows:

$$
C_{h}(\$)=c_{h} \cdot \overline{I_{i}}
$$




\subsubsection{Shortage Cost}

The shortage cost $\left(C_{s h}\right)$ represents the costs incurred during the time production has a depleted inventory. This is the cost incurred between this time and the period of a re-order. It includes costs of not using the machine and equipment involved in production.

$$
\begin{gathered}
C_{s h}=c_{s h} \cdot F_{t} \\
F_{t}=D \frac{y_{i}}{Q_{s}}
\end{gathered}
$$

where $y_{i}$ service as an indicator for when shortage is present in the equation. It can be activated or switched off during computation and holds two statuses which are 0 or 1 . Whereas $F_{t}$ stands for the amount of missing tools in system.

\subsubsection{Material Cost}

The material cost of purchasing the workpiece used in production is included for a more inclusive and comprehensive review of the total costs involved in production. It is a factor of the quantity of material and the cost per unit material purchase.

$$
C_{B}(\$)=Q_{B} \cdot c_{B}
$$

\subsubsection{Ordering Cost}

The ordering cost is described as a function of the unit cost of ordering tools, cycle time between orders and a variableterm. The variable term $z_{i}$ is used to consider the alternate conditions which are assumed constant in this present model. Such conditions for variability in unit ordering, shipping, delays and alternate reasons which could influence this cost could be expanded through this variable in future research modifications of this model. However, in this research work, the ordering cost is considered as constant of value 1 .

$$
C_{O}(\$)=C_{f} \frac{D}{Q} z_{i}
$$

\subsection{Basic Objective Function for Single Operations}

The objective function formed to minimize the production cost that involves the operation cost, shortage cost, holding cost, material cost and ordering cost is shown in the Equation (11). The cost of labor is not included in this function. The focal point of this function lies in the operational costs which is derived from the machining parameters and tool conditions.

$$
\begin{aligned}
& \qquad \operatorname{MinTC}\left(Q_{p} T_{c}\right) i=C_{o p}+C_{s h}+C_{h}+C_{B}+C_{O} \\
& \text { Minimised Total } \operatorname{Cost}\left(Q_{p}, T_{c}\right) i \\
& =\left(k_{0} t_{o p}+c_{h r} t_{o p}\right) Q_{p}+c_{s h} \sum_{i=0}^{n} D \frac{y_{i}}{Q_{s}}+\sum_{i=0}^{n} c_{h i} \bar{I}_{i}+Q_{B} \cdot c_{B}+C_{f} \frac{D}{Q_{o}} z_{i}
\end{aligned}
$$

\subsection{Constraints}

\section{Tool restrictions}


Some decision variables found in the model are the radial width of cut for the roughing operation $\left(w_{r}\right)$ and the axial depth of cut $\left(d_{r}\right)$. This radial width $\left(w_{r}\right)$ is connected to the number of passes and the width of the volume to machine $(W)$ :

$$
w_{r} \cdot N_{w}=W
$$

Also, the axial depth of cut $\left(d_{r}\right)$ which is connected to the number of axial passes $\left(N_{p}\right)$ and the height $(H)$ of the volume to machine is a decision variable:

$$
d_{r} \cdot N_{p}=H
$$

Limits are given to the width of radial cuts $\left(w_{r}\right)$ by the diameter of the tool $\left(D_{t}\right)$ :

$$
w_{r} \leq D_{t}
$$

The depths of axial cuts $\left(d_{r}\right)$ are also limited by the length of the tool flutes $\left(h_{f \max }\right)$ :

$$
d_{r} \leq h_{f \max }
$$

\section{Machine-tool constraints}

The power needed for the operation relies on the material removal rate $\left(M_{R R}\right)$ and the specific power rating of the workpiece material as seen in Equation (12). It can thus be inferred that at maximum machine power, the maximum metal removal rate $\left(M_{R R}\right)$ can be determined. This rate depends on the width of cut $\left(w_{r}\right)$, the feed $\left(f_{r}\right)$ to the depth $\left(d_{r}\right)$, as shown in the equation below:

$$
w_{r} * f_{r} * d_{r} \leq M_{R R}
$$

The material removal rate $\left(M_{R R}\right)$ can be denoted as:

$$
M_{R R} \leq \text { energy coefficent }(\eta) \cdot \frac{\text { maximum machine cutting power }}{\text { Unit power for the workpiece material }}
$$

In this case,

- The cutting speed rate is constrained by the machine's maximum spindle speed.

$$
\frac{1000 \cdot v_{r}}{\pi \cdot D_{t}} \leq N_{\max }
$$

- The achievable power is constrained by the maximum safe operational force.

$$
\frac{60 \cdot H P_{r}}{v_{r}} \leq F_{\max }
$$

- The cutting feed rate is constrained by the machine's maximum feed rate.

$$
f_{r} \leq f_{m \max }
$$

where $f_{m \text { max }}$ is the maximum feed of the machine, $F_{\max }$ are the maximum forces obtained from the machine and $N_{\max }$ is the maximum spindle speed of the machine.

Inventory and shortage restrictions

With restrictions of inventory as follows:

$$
\begin{gathered}
\left(I_{i-1}+Q_{p}\right)-I_{i}=Q_{t} i \\
I_{i} \leq A_{i}
\end{gathered}
$$




\section{Restrictions of shortage:}

$$
\begin{gathered}
Q_{t}-Q_{p}=F_{t} \\
Q_{p}-\bar{I}_{i}\left(y_{i}\right) \leq 0
\end{gathered}
$$

Finally, non-negativity is assumed for all the decision variables and binary variables:

$$
F_{t}, \bar{I}_{i}, A_{i} \geq 0 \text { and } y_{i}=0,1
$$

This project focuses on optimizing the process thought for quantity of tool in an inventory. Therefore the study remains within basic machine limitations or overlooks tool immersion and surface finish as constraints.

\section{Solution Methodology and Illustrative Example}

The model was implemented in "LINGO" by LINDO ${ }^{\circledast}$ systems. "LINGO" is a commercially available optimization modelling software used for building and solving mathematical optimization models. Its package build-up provides a language tool needed to build and design models as well as include needed solving tools within a compact integrated environment. It could be applied to linear, nonlinear, quadratic, integer and stochastic optimization problems. A seven core computer with 8 gigabytes of memory was used for the LINDO analysis to minimize processing time. Note that for each result the LINGO solver provided, it declared the solution as being only a local optimum, i.e. it could not fully guarantee a global optimum.

\subsection{Graphical Illustration}

The illustration in below depicts the policy of the model for the annual optimization of production in a manufacturing company whose primary task and operations is focused at metal works. This new tool policy includes the forecast of sales and the annual tool planning for production. The main objectives of this illustration is to show how the model can meet a high level of service in sales and a low inventory level of production. As the proposed model is founded on the principle of the Economic order quantity model (EOQ) [15], a generic inventory system adapted to include the influence of machining parameters is produced (Figure 5).

From the figure, the tool inventory system shows two different ordering quantity cycles which changes based on the variation of tools inventory depletion. By evaluating an accurate estimate of the production demand and correlating it with the productive tool life for machining tools, it is possible to determine the optimal order quantity $\left(Q_{t}\right)$ and optimal-order cycle $\left(T_{c}\right)$. A steep quantity slope due to reduced tool life or frequent tool damage would reduce the order cycle length. This can be prevented by accurately estimating the reorder point from the lead time in obtaining new tools [16]. A minimum safety threshold is also needed to protect against the impact of back-orders and offer enough time 


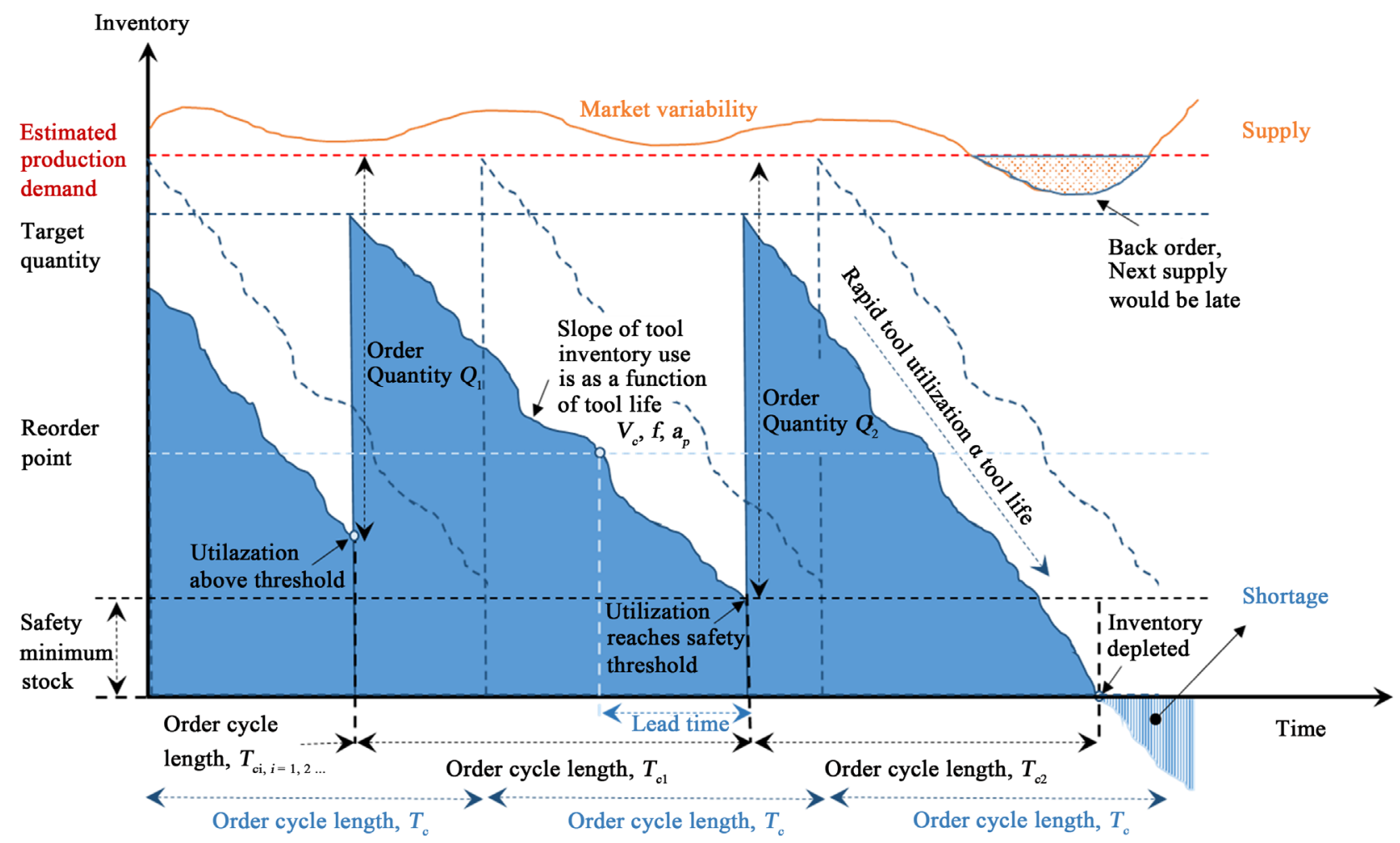

Figure 5. A generic review inventory system (adapted from Li and Cheng [10], Shang, Tadikamalla, J. Kirsch and Brown [17]) To the other sections. It is a result with more explanantion.

to react to depleting stock. Beyond this threshold the risks of reaching shortage is high.

It is worth noting that a machining tool has an expected productive life around its mean value; therefore, there exists more risk of failure cost for prolonged use of machining tool over this value. However, a reduction in running time of these tools will potentially increase the replacement quantity and thus re-ordering cost. Therefore, production inventory estimation is contingent on requirement needs based on trends and controlling the utilization time for the tools could be used to regulate the inventory system without influencing the integrity and quality of the product.

\subsection{Numerical Sample Case 1}

The example shown below was adapted from the work of Wang, Kim, Katayama and Hsueh [18]. In the study, the cost analysis of face milling amedium carbon steel (150 NHB) block, with a three-flute cemented carbide mill is performed. The tool diameter used is $25 \mathrm{~mm}$. The Taylor's tool life parameters utilized in this study were also obtained from literature [19]. Table 1 and Table 2 lists all the machine tool, cost and production parameters. The solution represented for this initial example, considers only a fixed demand of 2500 produced parts and determines ideal parameters needed to optimize inventory use and reduce cost. All constraints are based on realistic machine parameters. 
Table 1. Sample data utilized in numerical example 1; machine constants.

\begin{tabular}{cccc}
\hline \multicolumn{4}{c}{ Machine data } \\
\hline $\mathrm{Nmax}(\mathrm{rpm})$ & 1200 & $\max$ feed speed & $\mathbf{8 0 0 0}$ \\
$\mathrm{HPs}\left(\mathrm{w} / \mathrm{mm}^{3} / \mathrm{min}\right)$ & 59.2 & max cutting forces $(\mathrm{kN})$ & 2000 \\
$\mathrm{H} p \max (\mathrm{kw})$ & 22,000 & $\max$ spindle speed $(\mathrm{rpm})$ & 12,000 \\
Energy efficiency $\eta(\%)$ & 0.85 & & \\
\hline
\end{tabular}

Table 2. Sample data utilized in numerical example 1; cutting parameters, workpiece dimension and cost values.

\begin{tabular}{cccc}
\hline Cutting data & \multicolumn{2}{c}{ Cost data } \\
\hline feed per tooth $(\mathrm{mm} /$ tooth $)$ & $0.1-0.6$ & Quantity of workpiece purchased $(\mathrm{kg})$ & 500 \\
cutting speed $(\mathrm{m} / \mathrm{min})$ & $50-300$ & price of the tool $(\$)$ & 49.5 \\
Height $(\mathrm{mm})$ & 30 & cost per minute operation $(\$ / \mathrm{min})$ & 4 \\
Length $(\mathrm{mm})$ & 240 & raw material cost $(\$)$ per unit & 0.5 \\
Width $(\mathrm{mm})$ & 60 & Inventory cost & 0.5 \\
axial depth of cut $(\mathrm{mm})$ & 4 & Per ordering cost & $\$ 25$ \\
$\alpha$ & 0.2 & Holding cost per unit year & $\$ 9$ \\
$\beta$ & 4.0 & Time of operation (min) & 6 \\
$\gamma$ & 1.0 & Initial inventory & 100 \\
Taylor constant $\mathrm{K}$ & $2.086 \mathrm{E}+12$ & & \\
\hline
\end{tabular}

\section{Results and Discussion}

Solving the developed model using the $\mathrm{LINGO}^{\circledR}$ solver in Equation (11) gave the following cost breakdown as presented in Figure 6. From the figure, the main contributors to the total production costs were identified as the ordering costs, machine operations costs and holding costs. Ordering costs are known to vary based on the lead-time and unit cost of ordering a tool. As the lead-time to delivery increased, the ordering costs simultaneously increased. The operational cost on the other hand, is greatly susceptible to changes in tool life. An increment in the amount of tools following a poor performing tool life, was seen to significantly increase the incurred costs. The model also indicates the significant cost incurred from inventory of tools. Tool quantity stored during the production of the product bares an influence on its selling price. However, due to the successful minimization of the model, the separate cost of holding the safety stock as well as the shortage costs has become insignificant in the summation.

This elevated holding cost is due to the short cycle period of 5.5 days for reordering. A set of approximately 65 orders per year was obtained. The average forecast quantity of 7 units per order cycle was obtained from Equation (5). This resulted in an optimal order quantity $Q_{0}$ of about 38 units to minimize total costs of production. This can also be seen from Figure 7 and Figure 8 . The value obtained in contrary to an ideal EOQ model contains the inclusions of the sum of operational, shortage, holding, and material costs. An optimal ordering 


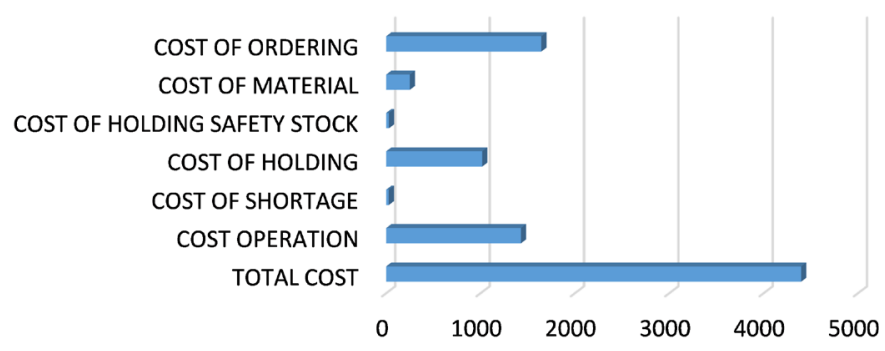

Figure 6. Bar chart result of the influence of various costs on total operating cost.

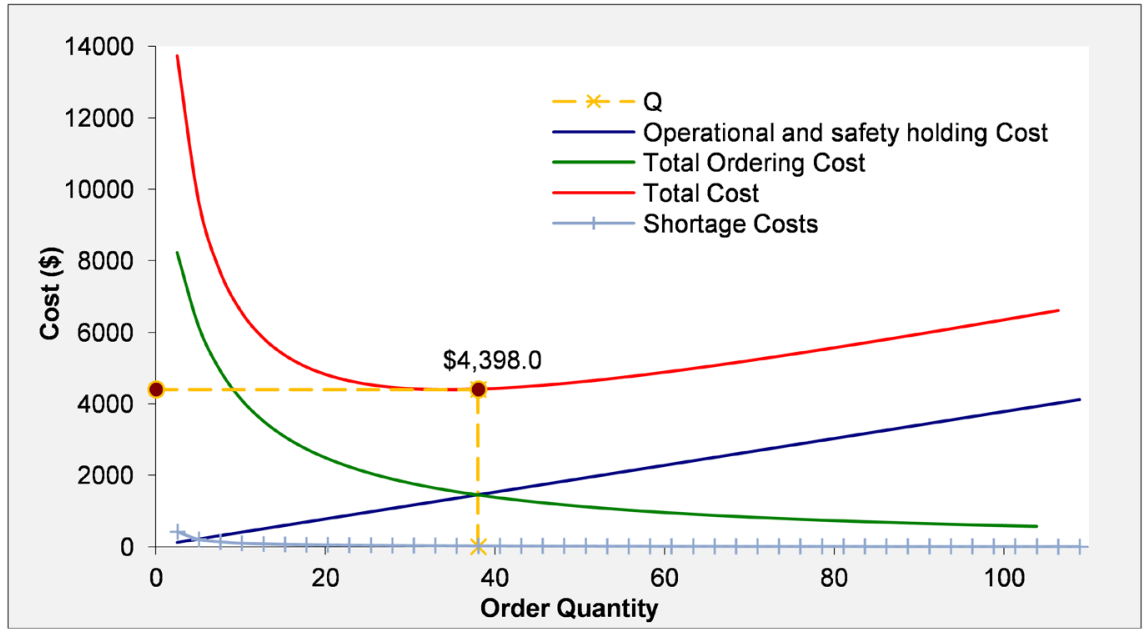

Figure 7. Schematic representation of the order optimization model with added machining op-erational cost.

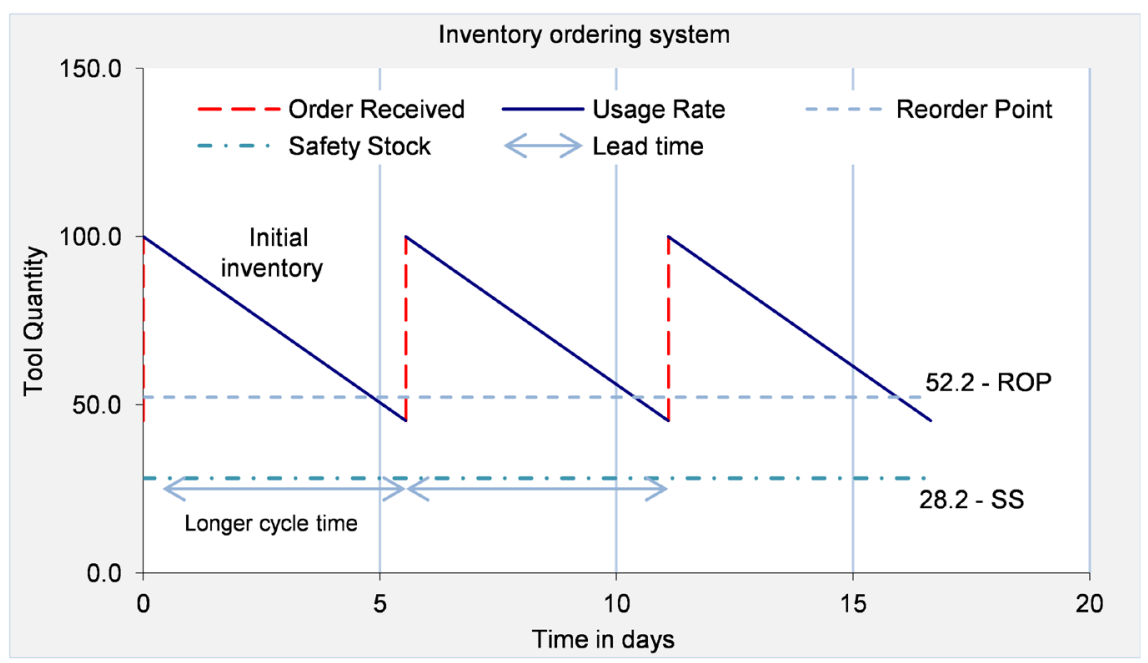

Figure 8. Schematic of inventory control system with a fixed demand.

quantity was obtained at the intersection of the ordering, sum of operations and safety holding costs. The results also indicated that a safety stock level of 28 units indicating the least amount in the inventory is needed to prevent a shortage situation. Furthermore, a value for re-ordering of stock to match lead time was deduced to be 52 units. 


\subsection{Numerical Sample Case 2}

Table 3 summarizes the data used in this numerical sample case 2. This example was adapted from the work of Parent, Songmene and Kenné [11] and modified to suit machining setup proposed in this study. A typical end milling operation of an alloyed steel part $(4140,4340)$, with a four-flute uncoated high speed steel (HSS) end mill is proposed for evaluation. The diameter of the tool is $19.05 \mathrm{~mm}$ ( 0.375 "). The chip load per tooth is estimated to be $0.05 \mathrm{~mm} /$ tooth and the speed between $30-45 \mathrm{~m} / \mathrm{min}$ with a hardness between $30-38$ HRC. The milling machine setup and initialization values, cost parameters as well as parameters for production are listed in the Table $1 \&$ Table 3 . The solution represented in this initial part, considers only a fixed demand of 5000 produced parts and determines ideal parameters needed to optimize inventory use and reduce cost. All constraints are established on realistic machine parameters.

\section{Results and Discussion}

Figure 9 presents results acquired using the $\mathrm{LINGO}^{\circledR}$ solver. The following cost breakdown presented in the Figure 10 was obtained solving the developed model

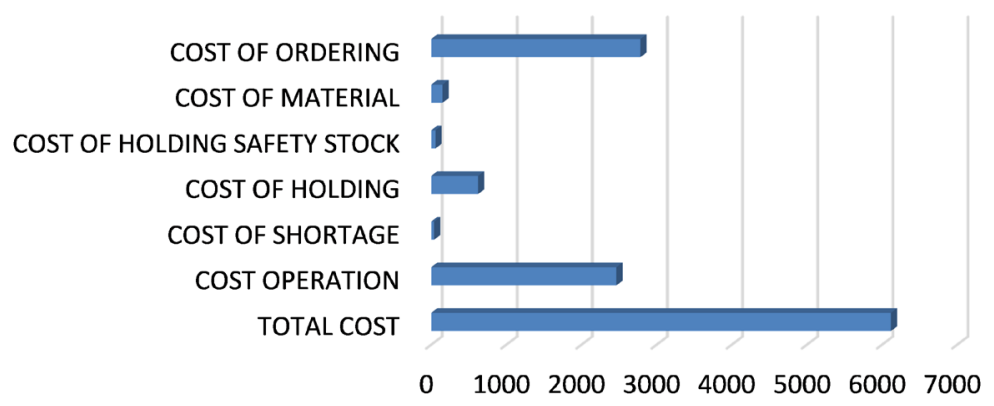

Figure 9. Bar chart result of the influence of various costs on total operating cost.

Table 3. Sample data utilized in numerical example 2; cutting parameters, workpiece dimension and cost values.

\begin{tabular}{cccc}
\hline Cutting data & & Cost data & \\
\hline Cutting feed rate $(\mathrm{mm} / \mathrm{min})$ & 4.01 & Mean Demand/year & 5000 \\
feed per tooth $(\mathrm{mm} /$ tooth $)$ & 0.05 & Quantity of workpiece purchased $(\mathrm{kg})$ & 200 \\
cutting speed $(\mathrm{m} / \mathrm{min})$ & 41 & price of the tool $(\$)$ & 90 \\
Height $(\mathrm{mm})$ & 25 & cost per minute operation $(\$ / \mathrm{min})$ & 4 \\
Length $(\mathrm{mm})$ & 100 & raw material cost $(\$)$ per unit & 0.75 \\
Width $(\mathrm{mm})$ & 60 & Inventory cost & 0.5 \\
axial depth of cut $(\mathrm{mm})$ & 0.063 & Per ordering cost & $\$ 30$ \\
$\alpha$ & 5 & Holding cost per unit year & $\$ 6$ \\
$\beta$ & 1.75 & Time of operation $(\mathrm{min})$ & 6 \\
$\gamma$ & 3.5 & & \\
$\lambda$ & 0 & & \\
\hline
\end{tabular}




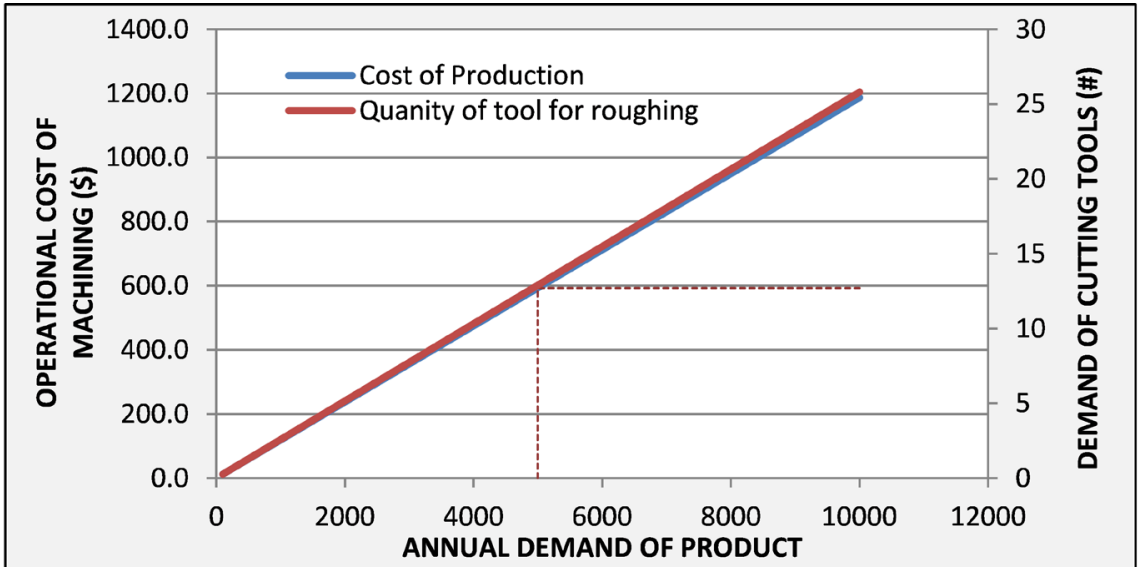

Figure 10. Schematic representation of tool quantity per order cycle needed at minimum total cost.

in Equation (11). From the figure, the main contributors to the total production costs were identified as the ordering and machine operations cost. However, this example presents a lower inventory holding costs. This is due to the lower cost of purchasing HSS tools and its influence in the combined optimization function. Due to the successful minimization of the model, the holding costs incurred for safety stock as well as the shortage costs remain insignificant in the overall summation.

For the numerical example, a set of 22 orders per year over an approximate 16 days cycle was obtained. The average forecast quantity of 13 units per order cycle was obtained from Equation (5). This resulted in an optimal order quantity $Q_{0}$ of about 54 units to minimize total costs of production. This can also be seen from Figure 11 and Figure 12. The value obtained in contrary to an ideal EOQ model contains the inclusions of the sum of operational, shortage, holding, and material costs. An optimal ordering quantity was obtained at the intersection of the ordering, sum of operations and safety holding costs. The results also indicated that a safety stock level of 57 units indicating the least amount in the inventory is needed to prevent a shortage situation. Furthermore, a value for re-ordering of stock to match lead time was deduced to be 105 units. An analysis of a controlled inventory system for the numerical example is illustrated in Figure 12.

\subsection{Sensitivity Analysis}

An in-depth sensitivity analysis of numerical sample case 2 is performed to establish influencing factors relevant to changes in operational costs, determine the influence of demand on inventory optimization and ascertain the key cost drivers of the model using actual industrial stochastic demand data.

\subsubsection{Cutting Parameters}

From an overview of the factors influencing the total cost of consequence, operational machining costs are selected to assess the effect of cutting factors. The 


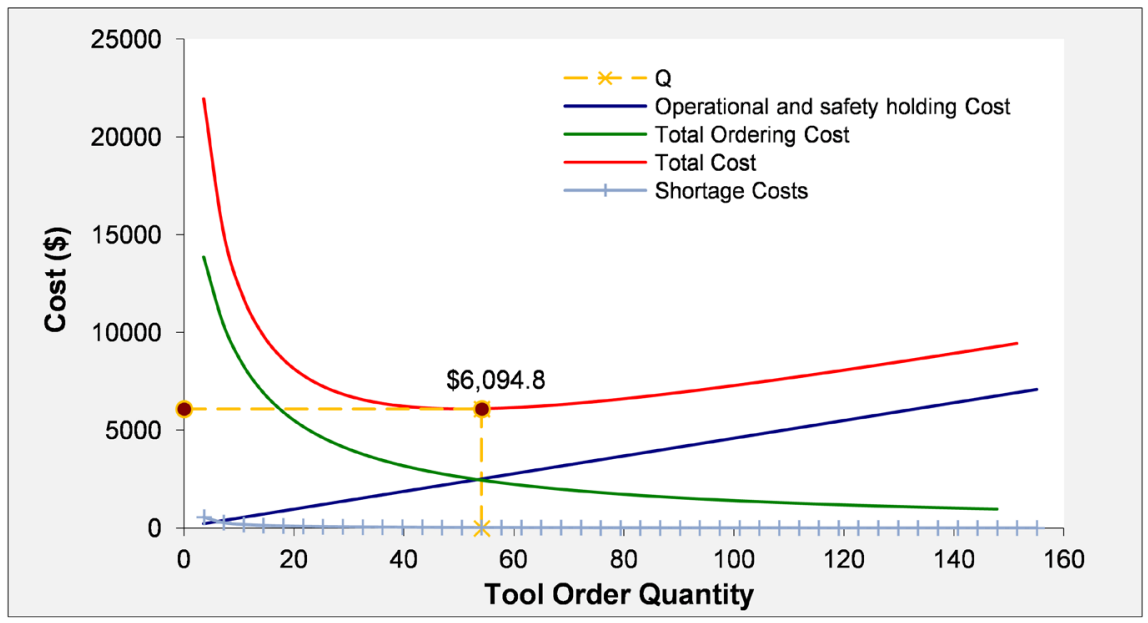

Figure 11. Schematic representation of the order optimization model with added machining op-erational cost.

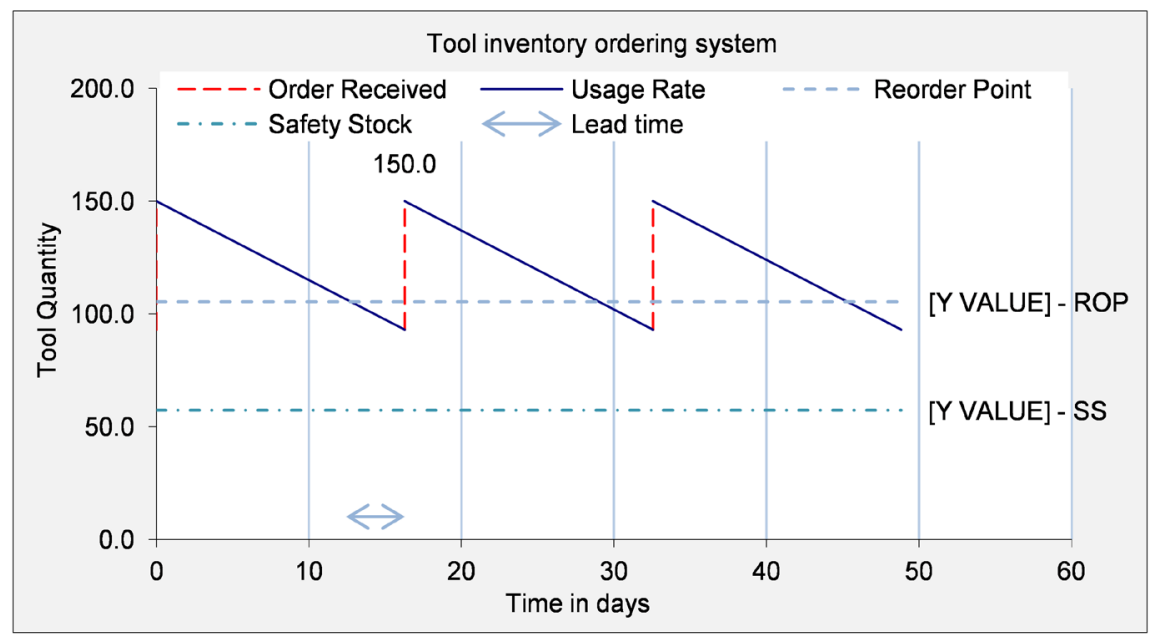

Figure 12. Schematic of inventory control system with a fixed demand.

most important variables for minimizing this cost area are the cutting speed and the feed rate. These significantly affect the tool life criterion and could create a rising cost avalanche during production. By fixing other factors involved to optimal levels, a plot of the relationship between speed and feed to total cost is shown in the Figure 13.

From Figure 13, it can be seen that as the speed increases a corresponding increase in machining cost is observed. This is expected based on the increased wear at such cutting parameters, however, with increased tool life a corresponding increase in machining cost was also observed. This situation can be explained by the factors controlling an optimum inventory ordering system. The improvement in the tool life changes the tool usage frequency and in consequence increases the holding costs of tools. Based on these changes and the consideration of lead time for ordering, a new optimal order quantity is calculated which is more than the previous to minimize the overall total cost of production. 


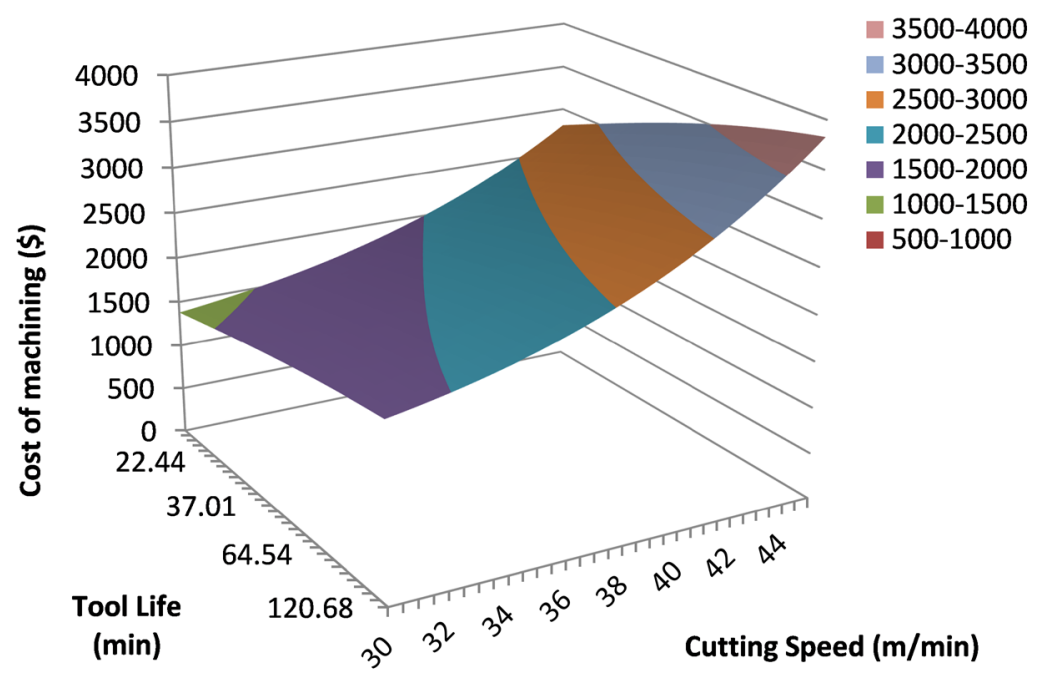

(a)

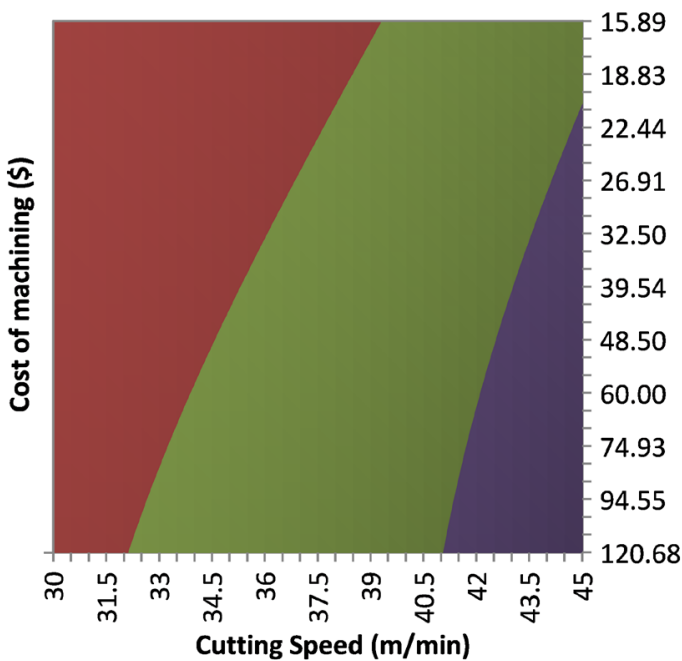

- 3000-4000

- 2000-3000

-1000-2000

- $0-1000$

Tool Life (min)

(b)

Figure 13. Trend of the machining cost based on cutting speed and tool life (a) 3D graph (b) Contour plot.

Similar observations are seen from the feed in Figure 14. An increase in feed to a maximum value of $0.09 \mathrm{~mm} /$ tooth also increases the machining cost. However, this increase and effect on the machining cost is more pronounced than that experienced by an increase in speed. Over the whole range of feed rates, a maximum costs increase of $\$ 4000$ was seen as compared to $\$ 2400$ with speed increase. The tool life changes based on changes in feed pose a significant effect of the optimal ordering quantity and thus the total cost. The most important variable to consider in estimating machining costs is therefore the feed rate.

\subsubsection{Demand Analysis and Cost Effects}

The estimated demand ideally influences total production cost since inclusive components costs do increase (Figure 15). However, a cost intensive phase is identified where optimal ordering quantity and safety stock levels are within 


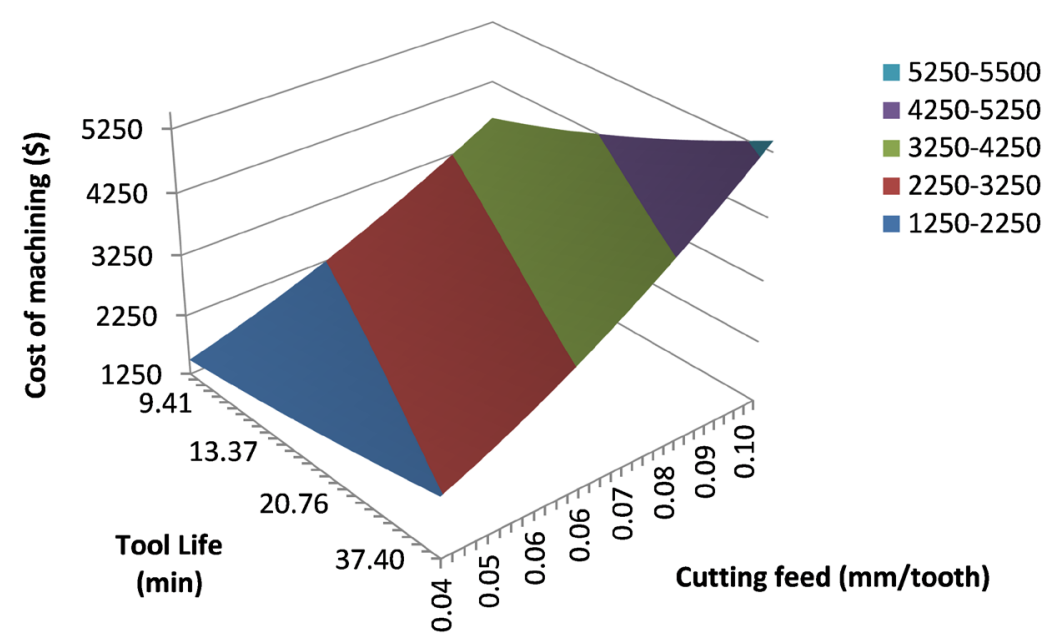

(a)

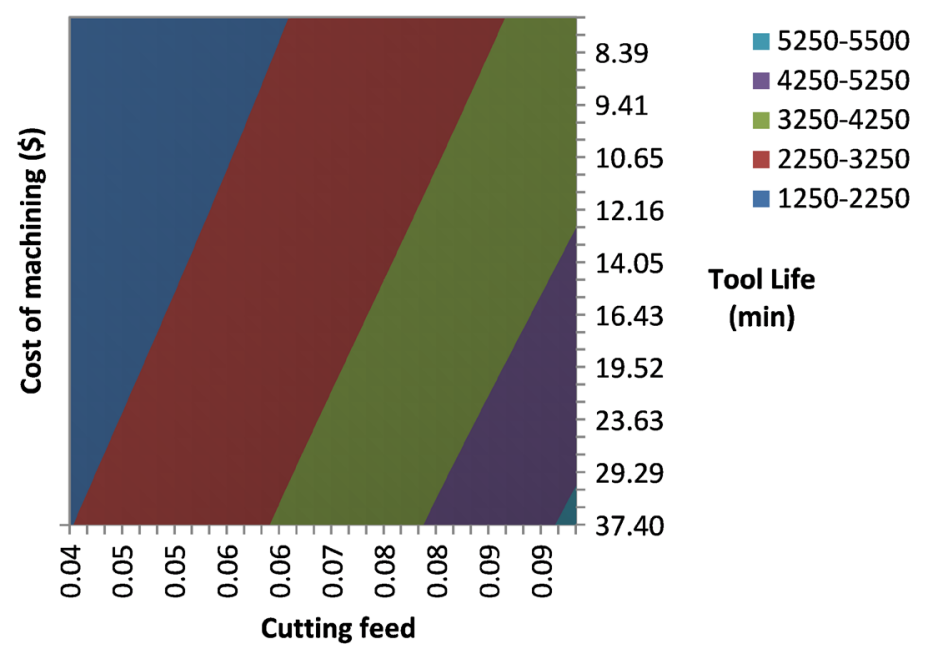

(b)

Figure 14. Trend of the machining cost based on feed and tool life (a) 3D graph (b) Contour plot..

proximity (Figure 16). It can be seen that there are two points in these graphs which should be identified when establishing cost expectations in production. The phase before point 1, indicates a non-profitable area of production with a steep increase in costs over a minimal demand. Within this stage fixed costs such as holding costs and inventory costs form a bulk of the total costs in production. As the demand increases, an increased effect of ordering and machining costs is experienced.

From Figure 16, we can also see an interplay between the safety stock and the optimum ordering quantity for minimized costs, which eventually steady out by increasing the safety stock to obtain optimize production costs. Overall costs from point 2 infer that an increased amount of safety stock is to higher demand is preferable. It is postulated that improved demands, reduces the costs impact of fixed expenses and thus increases profits. At such levels, an optimal safety stock quantity higher than the optimal ordering quantity is needed. 


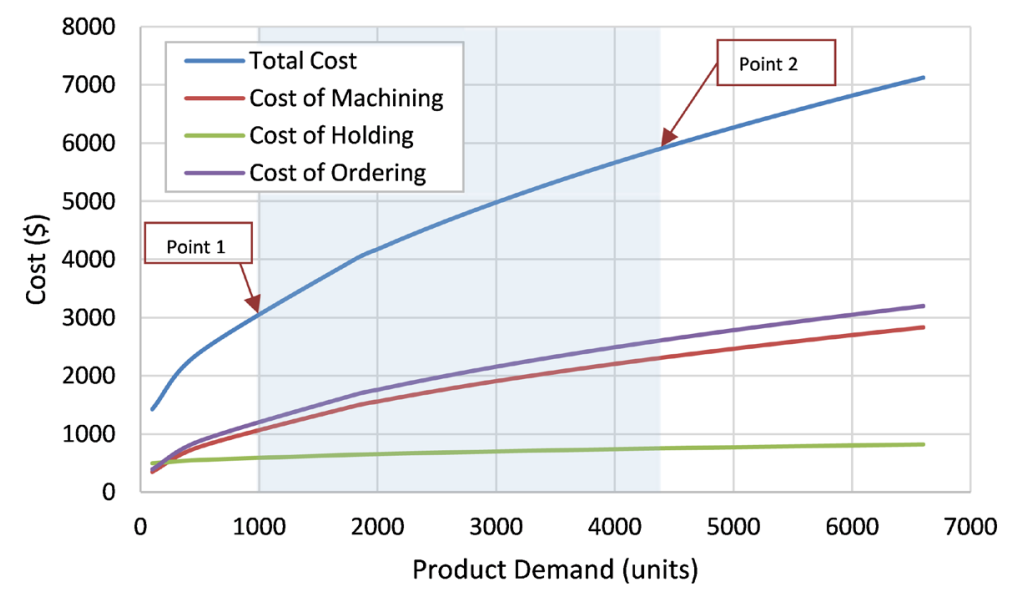

Figure 15. Trend showing the influence of change in demand to total cost.

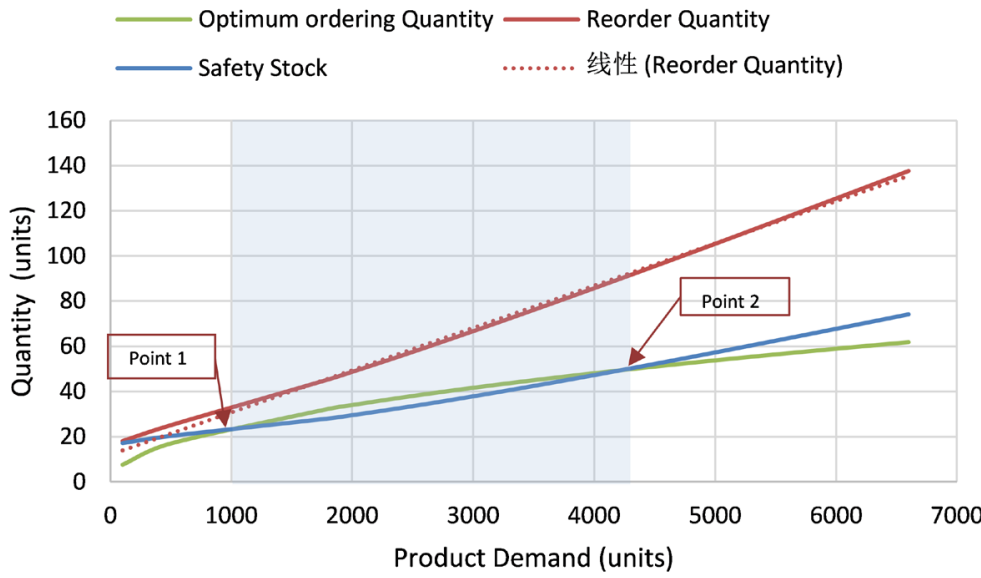

Figure 16. Trend showing the influence of change in demand tool quantity.

\subsubsection{Application of Demand Stochasticity}

A sensitivity analysis was carried out to ascertain the key cost drivers of the model using actual industrial stochastic demand data. The application of Holt-Winters (HW) forecasting was used to establish the trend for future demands. The current Holt-Winters method of exponential smoothing displays trend and seasonality and is characterized by three smoothing equations: the smoothing for level, equation for the trend and equation for seasonality [16] [20]. As the seasonal component is variable in unit production demand, the multiplicative method is used [21]. This applies when the size of the seasonal component is proportional to the trend level [22]. Figure 17 shows the results of the triple exponential smoothing HW method on the demand for produced units.

The basic equations for the Holt-Winters additive method are:

Equation for level (Overall smoothing):

$$
L_{t}=\alpha\left(\frac{Y_{t}}{S_{t-s}}\right)+(1-\alpha)\left(L_{t-1}+b_{t-1}\right)
$$

Equation for trend (Trend Smoothing): 


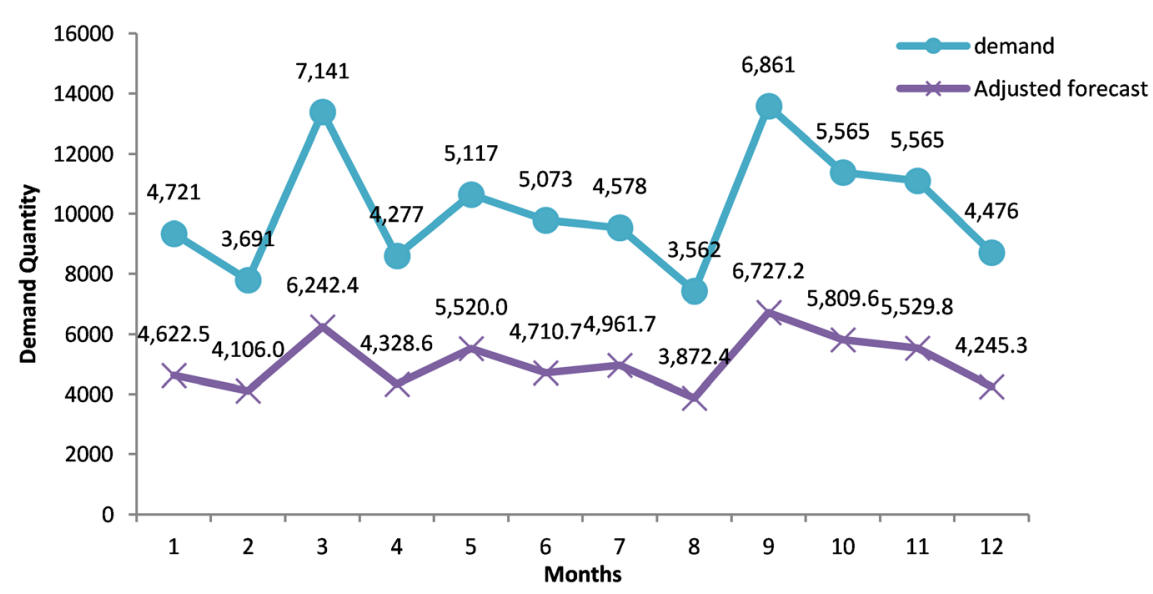

Figure 17. Trend showing Holt-Winters demand forecasting model for finished alloy steel parts.

$$
b_{t}=\beta\left(L_{t}-L_{t-1}\right)+(1-\beta) b_{t-1}
$$

Equation for seasonality (seasonal index):

$$
S_{t}=\gamma \frac{Y_{t}}{L_{t}}+(1-\gamma) S_{t-s}
$$

Forecast for m period equals:

$$
F_{t+m}=L_{t}+b_{t} m+S_{t-s m}
$$

where $Y_{t}$ are the observed value, $L_{t}$ represent the smoothing of variable in time $t, b_{t}$ the trend estimation and $S_{t}$ is the estimation of seasonality. The smoothing constants $\alpha, \beta, \gamma$ are in the interval $[0,1], m$ is the number of forecast periods and $s$ stands for the duration of seasonality (e.g. in months or quarters in a year).

Manufacturing industrial data figures utilized to establish the adequacy of the model can be found in Table 3. The sensitivity analysis of these results was conceivable by applying maximum and minimum ranges to the machine and user inputs considering what values may realistically be found in industry and accounting for price fluctuations. Industry indexes were used to collect average values for variables and rates. To identify the most important variables of the model, a One-Factor-at-a-Time (OFAT) sensitivity analysis approach was taken [23]. This would be a step in verifying the results of the cost comparison as well as a start in identifying the variables where variable uncertainty would have the highest cost impact. Sensitivity indices were calculated using an equation:

$$
\text { Sensitivity index }=D_{\max }-D_{\min } / D_{\max }
$$

where $D_{\min }$ and $D_{\max }$ are the minimum and maximum output costs resulting from changing dependent variables to the model.

The machine data and user inputs selected for sensitivity analysis and the applied maximum and minimum values are presented in Table 4.

The results of the sensitivity analysis for the variables in the model is shown in Table 4. Sensitivity analysis of the cost for the daily production period showed 
Table 4. Industrial varied data ranges for SA utilized in industrial application sample.

\begin{tabular}{cccccc}
\hline \multirow{2}{*}{ Cost variables } & \multicolumn{2}{c}{ Minimum } & \multicolumn{2}{c}{ Maximum } & Sensitivity \\
\cline { 2 - 5 } & Quantity & Cost value & Quantity & Cost value & $(\%)$ \\
\hline Machine Uptime (hr) & 1 & $\$ 17,646.62$ & 8 & $\$ 89,777.68$ & $80.34 \%$ \\
Demand (\$/year) & 1500 & $\$ 3547.49$ & 8000 & $\$ 7644.05$ & $53.59 \%$ \\
Ordering Costs (\$/unit) & 10 & 3764.443 & 50 & 7737.640 & $51.35 \%$ \\
Machining tool life (min) & 5 & 9646.872 & 160 & 5019.712 & $47.97 \%$ \\
Machine unit cost (Ko) (\$) & 3 & $\$ 5784.02$ & 20 & $\$ 9962.62$ & $41.94 \%$ \\
Cutting Feed (mm/tooth) & 0.04 & 5708.877 & 0.1 & 8360.683 & $31.72 \%$ \\
Cutting Speed (mm/min) & 30 & 5092.900 & 45 & 6741.792 & $24.46 \%$ \\
Machining tool cost per (\$/unit) & 60 & $\$ 5423.33$ & 120 & $\$ 6494.90$ & $16.50 \%$ \\
Lead time (days) & 3.5 & $\$ 6117.26$ & 14 & $\$ 6560.08$ & $6.75 \%$ \\
Shortage Costs (\$/unit) & 5 & $\$ 6112.16$ & 40 & $\$ 6119.85$ & $0.13 \%$ \\
\hline
\end{tabular}

that Machining uptime has a significant influence on the total cost. An increase in cost of approximately $\pm 10 \%$ per additional 1000 units demand was also identified as significant. Machine tool life and cutting feed rate have been identified as the most influential cutting variables to total costs. The cutting speed rate had marginal effect on both costs and tool life. Other costs variable such as shortage costs per unit and tool costs had low sensitivity values as their effects were mitigated from the minimization process. Optimization trend of ordered quantity over changing demand displayed a correlation with stochastic changes premised on a smoothing factor. This is shown in Figure 18 with the corresponding calculated production costs.

\subsection{Discussion of Influence of Production Variables}

From the results in Table 4 we can see that the time of operation of the machine as well as the demand are fundamental to deciding the total cost. The ordering cost in the numerical example shows some significant influence, however, this cost is not expected to exceed the machining costs during full production cycles. The core parameter of influence on machining is the cutting speed, which also affects the tool life. A scaled chart is shown in Figure 19 to illustrate the trends between factors and the influence of on cost. From the Figure 19, an increase in machining parameters (speed, feed rate) will cause a fall in tool-life and a corresponding increase in machining costs.

The implications of the research to industrial practice, shows an adequate method to estimate tools needed in a production system based on machining and clearly define the correlations between costs to process machining conditions. An enterprise could thus estimate create a production process which optimizes machining conditions while at the same time finding the optimal settings to tool allocation for storage. 


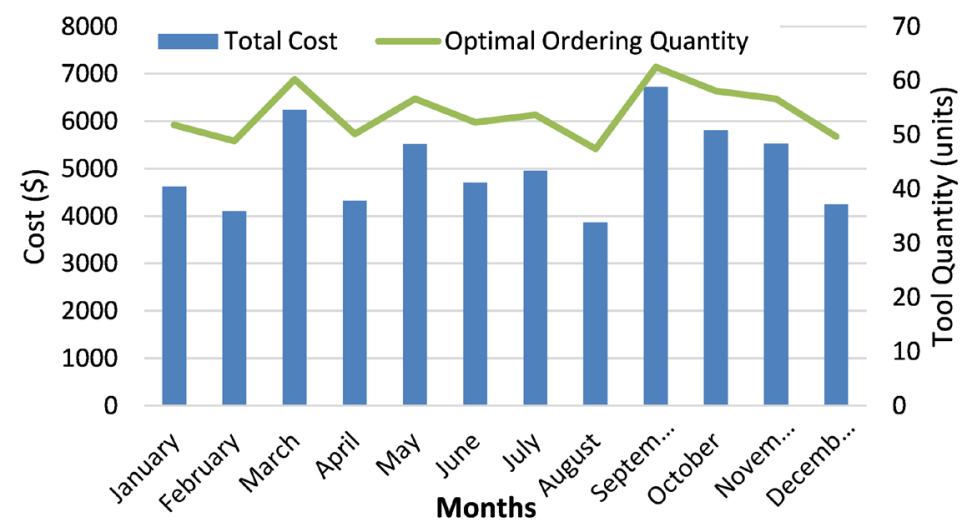

Figure 18. Optimal tool ordering quantity and cost for stochastic demand data.

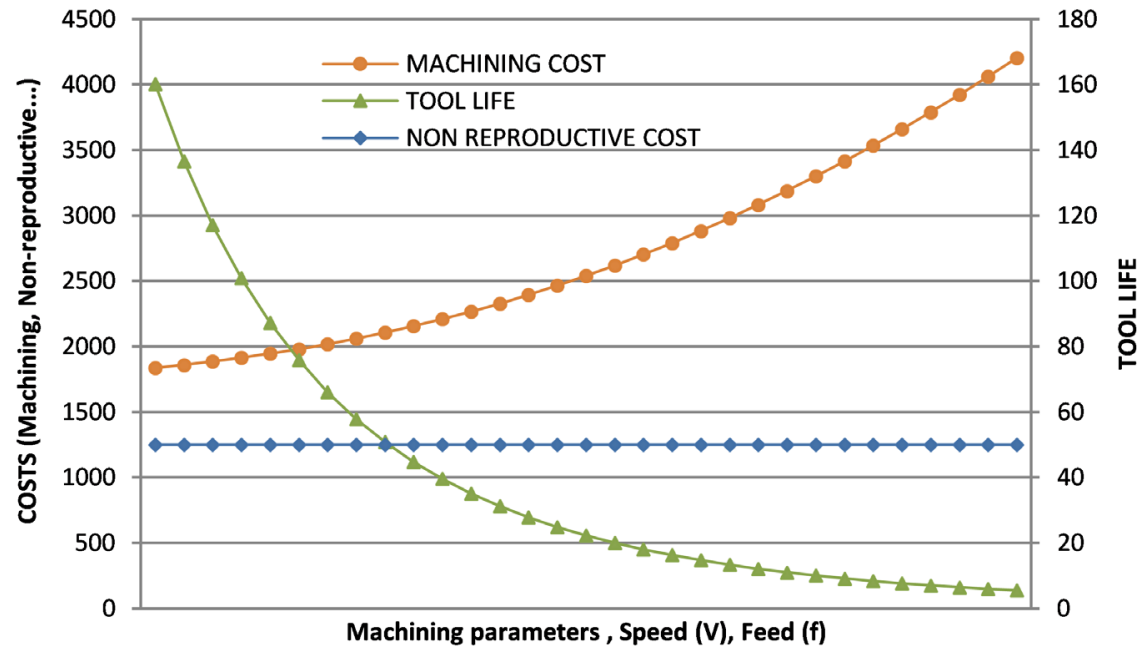

Figure 19. Graphical illustration of cost components against machining parameters and tool-life.

\section{Conclusions}

This study has presented an inventory control analysis premised on stochastic demand of machining tools. The model developed in this research is an optimum cost model governed by experimented machining conditions. Furthermore, the model is proposed to serve as a tool management policy for manufacturing industries. The fundamental considerations of the developed model includes the cutting tool, machining conditions and applied constraints. All of these are related to realistic conditions adapted to a practical production environment.

Optimization of the model solution was performed using Lingo, a commercially available optimization software. The simulation results obtained indicates that the feed rate is the most significant cutting parameter following its effect on machining costs. This in turn has a significant incremental effect on the overall production cost. Machine uptime and demand also showed significant effect on the total production cost. The process of optimizing the demand quantity, resulted in a cost-efficient optimum demand range characterized with a low safety 
stock and optimum ordering quantity. Additionally, an increase in the level of demand beyond the optimum range indicated that higher safety stock would be required. The application of Holt-Winters exponential smoothing forecasting technique further validates the outputs from this research.

Some limitations apply to the results of this research. Some of which are that the study focuses mainly on the use of a single cutting operation. In addition, an in-depth breakdown of cost influences from personnel, tool refurbishing and penalty costs are not considered. Fluctuations in ordering, holding, and unexpected inventory conditions are also not assessed.

In conclusion, several practical applications of this model can be obtained. This beginning with a single production operation concept as illustrated in this research to a more robust multi-operation manufacturing assembly. Future considerations of this research involve the development of a multiple-operational production approach with the inclusion of labor and penalty costs.

\section{Conflicts of Interest}

The authors declare no conflicts of interest regarding the publication of this paper.

\section{References}

[1] Tomotani, J.V. and de Mesquita, M.A. (2018) Lot Sizing and Scheduling: A Survey of Practices in Brazilian Companies. Production Planning \& Control, 29, 236-246. https://doi.org/10.1080/09537287.2017.1409370

[2] Gershwin, S.B. (2018) The Future of Manufacturing Systems Engineering. International Journal of Production Research, 56, 224-237. https://doi.org/10.1080/00207543.2017.1395491

[3] Conceicao, S.V., et al. (2015) A Demand Classification Scheme for Spare Part Inventory Model Subject to Stochastic Demand and Lead Time. Production Planning \& Control, 26, 1318-1331. https://doi.org/10.1080/09537287.2015.1033497

[4] Dimla Snr, D.E. (2000) Sensor Signals for Tool-Wear Monitoring in Metal Cutting Operations-A Review of Methods. International Journal of Machine Tools and Manufacture, 40, 1073-1098. https://doi.org/10.1016/S0890-6955(99)00122-4

[5] Teti, R., et al. (2010) Advanced Monitoring of Machining Operations. CIRP AnnalsManufacturing Technology, 59, 717-739. https://doi.org/10.1016/j.cirp.2010.05.010

[6] Arrazola, P.J., et al. (2013) Recent Advances in Modelling of Metal Machining Processes. CIRP Annals-Manufacturing Technology, 62, 695-718. https://doi.org/10.1016/j.cirp.2013.05.006

[7] Byrne, G., et al. (1995) Tool Condition Monitoring (TCM) - The Status of Research and Industrial Application. CIRP Annals-Manufacturing Technology, 44, 541-567. https://doi.org/10.1016/S0007-8506(07)60503-4

[8] Kouedeu, A.F., et al. (2014) Stochastic Optimal Control of Manufacturing Systems under Production-Dependent Failure Rates. International Journal of Production Economics, 150, 174-187. https://doi.org/10.1016/j.ijpe.2013.12.032

[9] Li, C.R., Sarker, B.R. and Yi, H.Z. (2014) An Optimal Stocking Policy for Machining Tools with Stochastically Distributed Lifespan and Demand. International Journal of Production Research, 52, 6175-6191. 
https://doi.org/10.1080/00207543.2014.918291

[10] Li, C.R. and Cheng, J.D. (2015) An Optimal Inventory Policy under Certainty Distributed Demand for Cutting Tools with Stochastically Distributed Lifespan. Cogent Engineering, 2.

[11] Parent, L., Songmene, V. and Kenné, J.P. (2007) A Generalised Model for Optimising an End Milling Operation. Production Planning \& Control, 18, 319-337. https://doi.org/10.1080/09537280701292501

[12] Conradie, P., Dimitrov, D. and Oosthuizen, G. (2016) A Cost Modelling Approach for Milling Titanium Alloys. 7 th Hpc 2016-Cirp Conference on High Performance Cutting, 46, 412-415.

[13] Braziotis, C., Tannock, J.D.T. and Bourlakis, M. (2017) Strategic and Operational Considerations for the Extended Enterprise: Insights from the Aerospace Industry. Production Planning \& Control, 28, 267-280. https://doi.org/10.1080/09537287.2016.1268274

[14] Neugebauer, R., et al. (2012) Resource and Energy Efficiency in Machining Using High-Performance and Hybrid Processes. Fifth Cirp Conference on High Performance Cutting, 1, 3-16. https://doi.org/10.1016/j.procir.2012.04.002

[15] Andrew-Munot, M. and Ibrahim, R.N. (2013) Development and Analysis of Mathematical and Simulation Models of Decision-Making Tools for Remanufacturing. Production Planning \& Control, 24, 1081-1100. https://doi.org/10.1080/09537287.2012.654667

[16] Syntetos, A.A., Boylan, J.E. and Disney, S.M. (2009) Forecasting for Inventory Planning: A 50-Year Review. Journal of the Operational Research Society, 60, S149S160. https://doi.org/10.1057/jors.2008.173

[17] Shang, J., et al. (2008) A Decision Support System for Managing Inventory at GlaxoSmithKline. Decision Support Systems, 46, 1-13.

[18] Wang, Y.-C., et al. (2018) Optimization of Machining Economics and Energy Consumption in Face Milling Operations. The International Journal of Advanced Manufacturing Technology, 99, 2093-2100. https://doi.org/10.1007/s00170-018-1848-6

[19] Wang, J., et al. (2002) Optimization of Cutting Conditions for Single Pass Turning Operations Using a Deterministic Approach. International Journal of Machine Tools and Manufacture, 42, 1023-1033. https://doi.org/10.1016/S0890-6955(02)00037-8

[20] Mascle, C. and Gosse, J. (2014) Inventory Management Maximization Based on Sales Forecast: Case Study. Production Planning \& Control, 25, 1039-1057. https://doi.org/10.1080/09537287.2013.805343

[21] Taylor, J.W. (2003) Short-Term Electricity Demand Forecasting Using Double Seasonal Exponential Smoothing. Journal of the Operational Research Society, 54, 799805. https://doi.org/10.1057/palgrave.jors.2601589

[22] Ferbar, L. and Vehove, A. (2013) The Improvement of the Holt-Winters Method for Intermittent Demand: A Case of Overnight Stays of Turists for Some Community in Republic of Slovenia. 45-52.

[23] Cunningham, C.R., et al. (2017) Cost Modelling and Sensitivity Analysis of Wire and Arc Additive Manufacturing. Procedia Manufacturing, 11, 650-657.

https://doi.org/10.1016/j.promfg.2017.07.163 


\section{Appendix}

1) Cost function components and intermediate variables

$C_{o p}:$ Total cost of operation (\$)

$C_{s h}$ : Total shortage cost (\$)

$C_{B}$ : Total workpiece material cost (\$)

$C_{h}$ : Total holding cost (\$)

$C_{o}$ : Total ordering cost (\$)

TC: Total production cost (\$)

\section{2) Decision variables}

$Q_{p}$ : Quantity of cutting tools required for production (tool/order)

$Q_{r}$ : Quantity of cutting tools required for roughing operation (tool/order) in period i

$Q_{f}$ : Quantity of cutting tools for finishing operation (tool/order)

$T_{c}$ : Tool ordering cycle length i.e. (length of time between placement of replenishment of tool orders) (time units)

3) Cost function components and intermediate variables

$c_{h r}, c_{h f}$ : Tool utilization cost per hour $(\$ / \mathrm{hr})$

$c_{h}$ : Expected unit holding cost $(\$ /$ tool $)$

$c_{B}$ : Cost per unit of workpiece (\$/unit)

$c_{p r}, c_{p f}:$ Tool Market price ( $\$ /$ tool)

$k_{0}$ : Cost of machine use per hour $(\$ / \mathrm{hr})$

$c_{s h}:$ Expected total annual shortage cost (\$/tool)

$L$ : Length per unit of workpiece to be cut $(\mathrm{mm})$

$W$ : Width per unit of workpiece to be cut $(\mathrm{mm})$

$H$ : Height per unit of workpiece to be cut $(\mathrm{mm})$

$w_{r}$ : Width (radial) of cut $(\mathrm{mm})$

$d_{r}$ : Depth (axial) of cut $(\mathrm{mm})$

$D_{t}$ : Diameter of the tool (mm)

$t_{o p r}, t_{o p f}$ : Cutting time per unit of workpiece, roughing and finishing operations, (min/unit)

$t_{0 r}, t_{0 f}$ : Tool life, roughing and finishing operations (min)

$k$. Taylor's equation constant

$v_{r}, v_{f}$ : Cutting speed, roughing and finishing operations $(\mathrm{m} / \mathrm{min})$

$f_{f} f_{r}$ : Feed per tooth, roughing and finishing operations ( $\mathrm{mm} /$ tooth)

$\alpha, \beta, \gamma, \lambda:$ Tool life parameters

$Q_{t}$ : Demand for tool required per year (in units)

$Q_{s}$ : Quantity of tool shortage (units)

$Q_{B}$ : Quantity of material ordered (units)

$D$ : Demand rate of products (products/year)

$F_{t}$ : Amount of missing tool in system (units)

$I_{i}$ : Average inventory at the end of the current period (units)

$I_{i-1}$ : Previous inventory (units) 
$A_{i}$ : Total capacity of inventory (units)

$\bar{I}_{i}$ : Possible holding inventory (units)

$z_{i}$ : Factor indicating variable ordering cost $(1,0)$ 